ence and a guide. As there is no counterpart to this volume in English, it is hoped that the book will stimulate British and American chemists and biologists to collaborate on a comparable work and, furthermore, that some linguist-biochemist will venture to trenslate the present volume.

$$
\text { M. RECHCIGL, JUN. }
$$

\section{LIFE OF VERTEBRATES}

\section{The Life of Vertebrates}

By Prof. J. Z. Young. Second edition. Pp. xv +820. (Oxford: Clarendon Press; London: Oxford University Press, 1962.) 70s. net.

T HE second edition of a path-finding book is always received with a heightened sense of occasion, because it is expected to show whether the path outlined by the author was the right one. Success or failure of the author's 'idiosyncrasies and ideas' in the presentation of his subject become evident by the degree of change in 'plan and basic balance' which a confident or disappointed author has felt obliged to introduce after the book's prolonged maiden voyage through the archipelago of criticism.

Prof. Young is confidently launching his Life of the Vertebrates on its second voyage in the full andmay it be said straight away-justified consciousness of success. No fundamental alteration in approach and treatment has had to be made. Some critics objected against the free combination of embryological, anatomical, physiological, biochemical, palæontological, and ecological aspects of vertebrate life within the covers of a single volume. It was stated that each of these facets was bound to suffer the insufficiency of cursory treatment. What was overlooked was the phenomenon of hybrid vigour, and what was underestimated was the thirst of the presentday student of biology, or for that matter of any other scientific subject, for synthesis: and thus this book was welcomed by teachers and students alike and has established itself as indispensable during the first dozen years of its existence.

This does not mean that its friends have not grumbled at times about this and that error of fact or about one or the other omission or too scanty a treatment of something considered essential: and those who have mistakenly tried to use the work as a reference book were undoubtedly among the most disappointed of its readers.

Meanwhile, the author has had his ear to the ground, and a considerable number of improvements have been introduced into the second edition. Notable among them are the thoroughly revised and amplified chapters dealing with sense organs and sensory function and with the function of the endocrine machinery. The study of echo-location and hearing in bats and the functional morphology of the ear in cetaceans have found their proper place in the relevant chapters. The chapters on electrical and luminous organs in fishes might perhaps have been given a littlo more attention in view of the many new findings in these fields. However, there are undoubtedly many more chapters about which similar wishes could be voiced. But a fulfilment of all these would be manifestly impossible in the framework of a single volume.

A number of technically less satisfactory illustrations have been replaced by redrawing or by new ones, and additional text figures have made their appearance.

The friends of the book will welcome the treatment for teething troubles which it has received from its author, and some of its adverse critics may be converted by the steadfastness of purpose with which its author has guided it forward to the second phase of its existence.

O. LOWENSTEIN

\section{SCOTTISH AND OTHER PLANKTON}

\section{Nature Adrift}

The Story of Marine Plankton. By Dr. James Fraser. Pp. v +178 (40 plates). (London: G. T. Foulis and Co., Ltd., 1962.) 45s. net.

WHEN Sir Alister Hardy's The World of Plankton appeared a few years ago its comprehensive excellence might have led one to suppose that there would be no occasion for another British book on plankton for another decade or more. Dr. Fraser has shown that one would have been wrong; in Nature Adrift he has produced a worthy companion volume to the earlier book. Since the two books are on the same subject they inevitably overlap a good deal, but there is sufficient difference in emphasis and content to make them complementary rather than conflicting, and anyone who owns one of them will find it pleasant, as well as profitable, to acquire the other.

Nature Adrift is an account of the plankton around the British Isles; only passing references are made to the tropics, the ocean depths or higher latitudes. The book begins with a really elementary introduction, which is followed by a good description of plankton apparatus and methods. Then come five chapters which survey the plants and animals of the plankton; these are very good indeed and provide a great deal of purely botanical and zoological information, including such an advanced topic as the complicated life-histories of the Doliolida and other Thaliacea. Anvone who really needs the elementary introduction may well find this part rather heavy going, but if he is thereby inspired to amplify his reading in a zoological text-book, so much the better, perhaps.

The last chapters include descriptions of plankton behaviour and distribution, and a masterly account of the subject that Dr. Fraser has made so much his own, the use of indicator species in interpreting water movements on a wide geographical scale, and the effects of these movements on the fisheries off Scotland and in the North Sea. The last chapter is a salutary discussion of the possible uses of plankton as a source of food for man.

The book is very well and copiously illustrated from a variety of pens and cameras, notably those of J. D. Milne, P. David and D. P. Wilson; it was presumably the question of expense that made it necessary to keop the coloured photographs so small. There is one curious defoct in the illustrations which might well be remedied in the next edition; whoreas all the animals and plants in text-figures are moticulously suppliod with seales of magnification. those in the plates are not. An unsophisticated reader might find it diffienlt to realize that the Ianthind in Plate XV, for example, is not in fact as big as the beer bottle in the neighbouring photograph.

The book is very well produced and a pleasuro to read. 